\title{
RISK BASED SCREENING FOR GESTATIONAL DIABETES MELLITUS AND ITS FETOMATERNAL OUTCOME.
}

\footnotetext{
1. MBBS, MS

Senior Registrar Department of Obstetrics \& Gynaecology

Peoples University of Medical and Health Sciences

PUMHS, Nawabshah.

2. MBBS, MD

Postgraduate Student of Medicine Peoples University Hospital Nawabshah.

3. MBBS, FCPS

Assistant Professor

Department of Medicine

Peoples University Hospital

Nawabshah.

4. MBBS, FCPS

Women Medical Officer

Hyderabad.

5. MBBS, FCPS

Postgraduate Student of Medicine Peoples University Hospital Nawabshah.
}

\section{Correspondence Address:}

Dr. Aasma Naz Qureshi

Department of Obstetrics \& Gynaecology

Peoples University of Medical and

Health Sciences

PUMHS, Nawabshah.

aasma.naz@yahoo.com

Article received on:

15/11/2018

Accepted for publication:

21/02/2019

Received after proof reading:

22/05/2019

\section{INTRODUCTION}

Gestational diabetes mellitus (GDM) is formally defined as "any degree of glucose intolerance with its onset or first recognition during pregnancy. ${ }^{1}$ It is seen in $1-14 \%$ of pregnancies but the prevalence in Pakistan depend upon the characteristics of the population screened. ${ }^{2}$ The prevalence of GDM in Pakistan varies from 3.2\% to $3.5 \%$ in different parts of country depending upon the geographical locations and diagnostic methods used. GDM has been found to be more prevalent in urban areas than in rural areas. ${ }^{3,4}$

Screening with risk factor alone has sensitivity of $63 \%$ and specificity of $56 \%$. Risk factors for GDM include age more than 35 years, history of poor obstetric outcome, higher parity, history of polyhydramnios in previous and current pregnancy, women with $\mathrm{BMl}>25 \mathrm{Kg} / \mathrm{m} 2$, history of prior neonatal death or macorosomic baby. GDM causessignificantmaternal and fetal complications including preeclampsia, poly hydramnios, fetal macrosomia, birth trauma, operative delivery, neonatal metabolic complications and perinatal death. During childhood development of obesity and diabetes, so subsequent development of mother diabetes mellitus is related to GDM. ${ }^{5}$

Risk-based assessment is at least the minimum number of women and reduce the burden on health care systems, while increasing the number of missed diagnosis. Contrary to the fact, association of adverse maternal and fetal outcome in an untreated woman with GDM and 
medico-legal consequence of a missed diagnosis prompts most clinicians to follow universal screening, despite differential guidelines. ${ }^{6,7}$

The rational behind my study ws that as women with GDM are carrying high risk pregnancies, a planned and vigilant care be provided to such women, in order to minimize the complications and hence optimize outcome.

\section{METHOD}

This Cross sectional study consiston 86 patients, conducted at Obstetrics and Gynaecology Unit-II at Liaquat University Hospital Hyderabad.

Women with age (20-35) with parity upto 5, with GDM were included in this study. Patients with pre-existing diabetes and those who are not giving consent, were excluded from the study. The Women GDM included in the study by identification of risk factors from history an examination including obesity (BMI $>25 \mathrm{Kg} /$ $\mathrm{m} 2$ ), past obstetrical history of macrosomia, polyhydramnios, shoulder dystocia, gestational diabetes, still birth or early neonatal death and/ or macrosomia and polyhydramnios (AFI $>25 \mathrm{~cm}$ ) in current pregnancy (uterus large for dates on examination and confirmed on ultrasound) and family history of diabetes in first degree relatives.

\section{RESULTS}

A total of 86 Women with GDM attending OPD for antenatal care at tertiary care hospital Hyderabad were included in this study. Most of the women were 21 to 30 years of age as shown in Table-l. The average age of the women was $26.23 \pm 4.03$ years similarly mean parity and gestational age of the women is also given in Table-Il. There were $17(19.77 \%)$ women had primipara (parity $=1$ ) and $69(80.23 \%)$ had multipara (partiy 2 to 5 ) as presented in table 1. Most of the women belonged to urban area as shown in Table-l. Forty eight (55.81\%) were un-booked cases and 38(44.19\%) booked cases (Table-I).

Frequency of factors leading to gestational diabetes mellitus is previous history of previous GDM; $66.3 \%$, Previous history of macrosomia $54.7 \%$, Polyhydramnios in current pregnancy
$51.2 \%$, macrosomia in current pregnancy $44.2 \%$, previous history of shoulder dystosia $41.9 \%$, and women with $\mathrm{BMl}>25 \mathrm{~kg} / \mathrm{m} 2$ was observed in $32.6 \%$ cases.

GDM causes significant maternal and fetal complications including preeclampsia $51.2 \%$, preterm $23.3 \%$, and operative delivery $29.1 \%$, as well as fetal death was observed in $21(24.4 \%)$ in which $17.44 \%$ still birth (15/86) and $6.98(6 / 86)$ were neonatal death.

Rate of previous history of previous GDM factor was significantly high in 31 to 35 years of age women while women with BMl $>25 \mathrm{~kg} /$ $\mathrm{m} 2$ and poly hydramnios in current pregnancy was significantly high in 18 to 20 years of age. Factors leading to GDM like previous history of macrosomia, previous history of shoulder dystosia and macrosomia in current pregnancy were not significant among different age groups in this study as presented in Table-III. Similarly fetomaternal outcomes were also not significant among different age groups of the women as shown in Table-IV.

Factors leading to GDM and fetomaternal outcomes were also observed with respect to parity but insignificant difference was observed as presented in Table-V.

\begin{tabular}{|c|c|c|}
\hline Variable & No. Patients & Percentage \\
\hline \multicolumn{3}{|l|}{ Age } \\
\hline $18-20$ years & 7 & $8.14 \%$ \\
\hline 21-30 years & 65 & $75.56 \%$ \\
\hline $31-35$ years & 14 & $16.28 \%$ \\
\hline \multicolumn{3}{|c|}{ Parity Distribution } \\
\hline Primipara & 17 & $19.77 \%$ \\
\hline Multipara & 69 & $80.23 \%$ \\
\hline \multicolumn{3}{|c|}{ Locality of the Women } \\
\hline Rural & 33 & $38.37 \%$ \\
\hline Urban & 53 & $61.63 \%$ \\
\hline \multicolumn{3}{|c|}{ Booking Status } \\
\hline Unbooked & 48 & $55.81 \%$ \\
\hline Booked & 38 & $44.19 \%$ \\
\hline \multicolumn{3}{|c|}{ Table-I. Patients variables $\mathbf{N}=86$} \\
\hline
\end{tabular}




\begin{tabular}{|c|c|c|c|c|}
\hline \multicolumn{2}{|c|}{ Descriptive Statistics } & Age (Years) & Parity & $\begin{array}{l}\text { Gestational Age } \\
\text { (Weeks) }\end{array}$ \\
\hline \multicolumn{2}{|l|}{ Mean } & 26.23 & 2.47 & 37.65 \\
\hline \multicolumn{2}{|l|}{ Std. Deviation } & 4.03 & 1.07 & 1.35 \\
\hline \multirow{2}{*}{ 95\% Confidence Interval for Mean } & Lower Bound & 25.37 & 2.24 & 37.36 \\
\hline & Upper Bound & 27.10 & 2.69 & 37.94 \\
\hline \multicolumn{2}{|l|}{ Median } & 27 & 2 & 37.50 \\
\hline \multicolumn{2}{|l|}{ Inter quartile Range } & 7 & 1 & 2 \\
\hline \multicolumn{2}{|l|}{ Minimum } & 20 & 1 & 35 \\
\hline \multicolumn{2}{|l|}{ Maximum } & 35 & 5 & 40 \\
\hline
\end{tabular}

Table-II. Descriptive statistics of the women $(n=86)$

\begin{tabular}{|c|c|c|c|c|c|}
\hline \multirow[b]{2}{*}{ Risk factor for GDM } & \multicolumn{4}{|c|}{ Age Groups (Years) } & \multirow[b]{2}{*}{ P-Value } \\
\hline & $\begin{array}{l}18 \text { to } 20 \\
(n=7)\end{array}$ & \multicolumn{2}{|c|}{$\begin{array}{l}21 \text { to } 30 \\
(n=65)\end{array}$} & $\begin{array}{l}31 \text { to } 35 \\
(n=14)\end{array}$ & \\
\hline Previous history of macrosomia & $5(71.4 \%)$ & \multicolumn{2}{|c|}{$33(50.8 \%)$} & $9(64.3 \%)$ & 0.42 \\
\hline Previous history of shoulder dystosia & $3(42.9 \%)$ & \multicolumn{2}{|c|}{$27(41.5 \%)$} & $6(42.9 \%)$ & 0.99 \\
\hline Previous history of previous GDM & $1(14.3 \%)$ & \multicolumn{2}{|c|}{$45(69.3 \%)$} & $11(78.6 \%)$ & $0.008^{*}$ \\
\hline Women with $\mathrm{BMI}>25 \mathrm{~kg} / \mathrm{m}^{2}$ & $7(100 \%)$ & \multicolumn{2}{|c|}{$15(23.1 \%)$} & $6(42.9 \%)$ & $0.0005^{\star}$ \\
\hline Macrosomia in current Pregnancy & $4(57.1 \%)$ & \multicolumn{2}{|c|}{$28(43.1 \%)$} & $6(42.9 \%)$ & 0.77 \\
\hline Polyhydramnios in current Pregnancy & $6(85.7 \%)$ & 35 & $8 \%)$ & $3(21.4 \%)$ & $0.01^{*}$ \\
\hline \multicolumn{6}{|c|}{$\begin{array}{l}\text { Table-III. Frequency of factors leading to gestational diabetes mellitus with respect to age groups } \\
\text { Chi-Square test applied for each factor separately. }{ }^{*} \text { Significant }\end{array}$} \\
\hline \multirow[b]{2}{*}{ Outcome } & \multicolumn{4}{|c|}{ Age Groups (Years) } & \multirow[b]{2}{*}{ P-Values } \\
\hline & $\begin{array}{l}18 \text { to } 20 \\
(n=7)\end{array}$ & \multicolumn{2}{|c|}{$\begin{array}{l}21 \text { to } 30 \\
(n=65)\end{array}$} & $\begin{array}{c}31 \text { to } 35 \\
(n=14)\end{array}$ & \\
\hline $\begin{array}{l}\text { Fetal Outcome } \\
\text { Alive } \\
\text { Still Birth } \\
\text { Neonatal Death }\end{array}$ & $\begin{array}{l}6(85.7 \%) \\
0(0 \%) \\
1(14.3 \%)\end{array}$ & \multicolumn{2}{|c|}{$\begin{array}{l}46(70.8 \%) \\
15(23.1 \%) \\
4(6.2 \%)\end{array}$} & $\begin{array}{l}13(92.9 \%) \\
0(0 \%) \\
1(7.1 \%)\end{array}$ & 0.17 \\
\hline \multicolumn{6}{|l|}{ Maternal Outcome } \\
\hline Preterm delivery & $1(14.3 \%)$ & \multicolumn{2}{|c|}{$13(20 \%)$} & $6(42.9 \%)$ & 0.15 \\
\hline Preeclampsia & $5(71.4 \%)$ & \multicolumn{2}{|c|}{$29(44.6 \%)$} & $10(71.4 \%)$ & 0.10 \\
\hline Operative delivery & $2(28.6 \%)$ & \multicolumn{2}{|c|}{$21(32.3 \%)$} & $2(14.3 \%)$ & 0.40 \\
\hline \multicolumn{6}{|c|}{$\begin{array}{l}\text { Table-IV. Comparison for fetomaternal outcome in gestational diabetes mellitus among age groups } \\
\text { Chi-Square test applied for each outcome separately }\end{array}$} \\
\hline Risk Factor for GDM & Primipar & $1=17)$ & Mult & rity $(n=69)$ & P-Value \\
\hline Previous history of macrosomia (Weight $>4 \mathrm{~kg}$ ) & $6(52$ & & & $55.1 \%)$ & 0.87 \\
\hline Previous history of shoulder dystosia & $9(52$ & & & $39.1 \%)$ & 0.30 \\
\hline Previous history of previous GDM & $10(5$ & & & $68.1 \%)$ & 0.46 \\
\hline Women with $\mathrm{BMI}>25 \mathrm{~kg} / \mathrm{m}^{2}$ & $8(47$ & & & $(29 \%)$ & 0.15 \\
\hline Macrosomia in current Pregnancy & $7(41$ & & & 44.9\%) & 0.78 \\
\hline Polyhydramnios in current Pregnancy & $10(5$ & & & $49.3 \%)$ & 0.48 \\
\hline
\end{tabular}

\section{DISCUSSION}

During pregnancy period, first detected or develops of intolerance of carbohydrates is called Gestational diabetes mellitus (GDM). ${ }^{8}$
Perinatal morbidity and mortality were increased in Gestational diabetes mellitus, as well as more prone to complications in the mother and baby, results that deserve proper identification and 
treatment. ${ }^{9}$ However, the growing population of diabetes is 21 million people ( $7 \%$ of the population) have some form of diagnosed diabetes ${ }^{10}$ another 6 million people may be undiagnosed. ${ }^{11}$

The variations in GDM prevalence depending on the strata of maternal risk factors observed in our study are largely in agreement with earlier studies. ${ }^{121,122}$ In our study frequency of factors leading to gestational diabetes mellitus are previous history of previous GDM; 66.3\%, Previous history of macrosomia $54.7 \%$, Polyhydramnios in current pregnancy $51.2 \%$, macrosomia in current pregnancy $44.2 \%$, previous history of shoulder dystocia $41.9 \%$, and women with $\mathrm{BMl}>25 \mathrm{~kg} /$ $\mathrm{m}^{2}$ was observed in 32.6\%. GDM's biggest difference is for early pregnancy, obesity and illness symptoms in mode high. Relationship between obesity, high pressure and blood safety is well documented, and continues in pregnancy. Regarding relation of increased BMI, an international study conducted by by O'Reilly et al and reported that gestational elevated body mass index (BMI) was associated factor with persistent hyperglycemia in women who have had gestational diabetes mellitus. Study also concluded that breastfeeding may be beneficial to provide metabolic effects in women with diabetes mellitus. ${ }^{12}$ A large body of data shows that maternal obesity is a significant risk factor for the development of GDM. High BMI before pregnancy is three- fold risk for obese women compared to non -obese women. Another study reported maternal obesity is increased threefold risk factor and more prone to three-fold risk developed GDM. ${ }^{13}$ Family history of type 2 diabetes of GDM more relevant in multiparous then the parous women ${ }^{14}$ Kabiru et al concluded that as maternal weight increases, the likelihood of GDM also increase. ${ }^{15}$

Our study reported women associated with GDM have more developed complications like pregnancy-induced hypertension and preeclampsia $51.2 \%$, cesarean section $29.1 \%$ and preterm delivery $23.3 \%$, while and international study also supported. ${ }^{16}$ A case-control study reported gestational diabetes is also linked with hypertension before conceive or during initial phase of pregnancy. ${ }^{17}$

One Study conducted on 381 women associated with hypertension or prehypertension (the latter being defined in the study as 120-139/80-89 $\mathrm{mmHg}$ ) compared with control 942 subjects, the results of this study showed controlled group is slightly increased risk while other group known case of hypertension was associated with a twofold increase in risk of gestational diabetes."

A large study by Xionget $a /{ }^{8}$ detected preeclampsia in $2.7 \%$ of 2755 patients with GDM compared with only $1.1 \%$ of 108664 patients with normal pregnancy (adjusted OR $=1.3 ; 95 \%$ Cl 1.20, 1.41). Similar results were observed for gestational hypertension.

In our study, fetal death was observed in $21(24.4 \%)$ in which $17.44 \%$ still birth (15/86) and $6.98(6 / 86)$ were neonatal death. While compare with study of Casey et al reported increased risk of stillbirth is not associated with the GDM. ${ }^{19}$ The principal pregnancy complication attributable to GDM is excessive fetal size or macrosomia. ${ }^{20}$ Fetal macrosomia is the result of fetal hyperinsulinemia which resulted in the transfer of in glucose and other nutrients. ${ }^{21}$

\section{CONCLUSION}

Gestational Diabetes Mellitus is associated with increased morbidity in mothers and fetus. Early detection and intervention is important because it improves pregnancy outcome. We found that previous GDM, Macrosomia and polyhydrominois was highly significant to the risk of GMD. It is recommended that pregnant women over the age of 30 and high BMI screened for GDM. As women with GDM are carrying high risk pregnancies, a planned and vigilant care be provided to such women, in order to minimize the complications and hence optimize outcome.

\section{Copyright $@ 21$ Feb, 2019.}

\section{REFERENCES}

1. American Diabetes Association. Diagnosis and classification of diabetes mellitus. Diabetes Care. 2006; 29 Suppl 1:S43-8. 
2. Jovanovic L, Pettitt DJ. Gestational diabetes mellitus. JAMA. 2001; 286:2516-8.

3. Hakeem R, Fawwad A. Diabetes in Pakistan: Epidemiology, determinants and prevention. J Diabetology. 2010; 3(4):1-13.

4. Seshiah V, Balaji V, Balaji MS, Panneerselvam A, Kapur A. Pregnancy and diabetes scenario around the world: India Int J Gynaecol Obstet. 2009; 104(1):S35-8.

5. Ferrara A, Hedderson MM, Quesenberry CP, Selby JV. Prevalence of gestational diabetes mellitus detected by the National Diabetes Data Group or the Carpenter and Coustan plasma glucose thresholds. Diabetes Care. 2002; 25:1625.

6. Hossein-Nezhad A, Maghbooli Z, Vassigh AR, Larijani $B$. Prevalence of gestational diabetes mellitus and pregnancy outcomes in Iranian women. Taiwan $\mathrm{J}$ Obstet Gynecol. 2007; 46(3):236-41.

7. Moses RG, Cheung NW. Universal screening of gestational diabetes mellitus. Diabetic Care. 2009; 32:1349-51.

8. WHO Study Group on Prevention of Diabetes Mellitus. Prevention of diabetes mellitus, Report of a WHO Study Group. Technical Report Series 844. Geneva: World Health Organisation; 1994.

9. Pettitt DJ, Bennett P, Saad MF, Charles MA, Nelson RG, Knowler WC. Abnormal glucose tolerance during pregnancy in Pima Indian women: Long-term effects on offspring. Diabetes. 1991; 40 (Suppl 2):126-30.

10. Baptiste-Roberts K, Barone BB, Gary TL. Risk factors for type 2 diabetes among women with gestational diabetes: A systematic review. Am J Med. 2009; 122:207.

11. Boinpally $T$, Jovanovic L. Management of type 2 diabetes and gestational diabetes in pregnancy. Mt Sinai J Med. Jun 2009; 76(3):269-80.
12. O'Reilly MW, Avalos G, Dennedy MC, O'Sullivan EP, Dunne F. Atlantic DIP: High prevalence of abnormal glucose tolerance post partum is reduced by breastfeeding in women with prior gestational diabetes mellitus. Eur J Endocrinol. Dec 2011; 165(6):953-9.

13. Villamor $E$, Cnattingius $S$. Inter pregnancy weight change and risk of adverse pregnancy outcomes: A population- based study. Lancet. 2006; 36(4):1164-70.

14. Retnakaran R, Connelly PW, Sermer M. The impact of family history of diabetes on risk factors for gestational diabetes. Clin Endocrinol (Oxf). 2007; 4(3):928-32.

15. Kabiru W, Raynor D. Obstetric outcomes associated with increase in BMI category during pregnancy. Am J Obstet Gynecol. 2004; 9(4):928-32.

16. Weeks JW, Major CA, de Veciana M, Morgan MA. Gestational diabetes: does the presence of risk factors influence perinatal outcome? Am J Obstet Gynecol. 1994; 171:1003-7.

17. Hedderson MM, Ferrara A. High blood pressure before and during early pregnancy is associated with an increased risk of gestational diabetes mellitus. Diabetes Care. Dec 2008; 31(12):2362-7.

18. Dukler D, Porath A, Bashiri A, Erez O, Mazor M. Remote prognosis of primiparous women with preeclampsia. Eur J Obstet Gynecol Reprod Biol. 2001; 96:69-74.

19. Casey B, Lucas MJ, Mcintire D, Leveno KJ. Pregnancy outcome in women with gestational diabetes compared with the general obstetric population. Obstet Gynecol. 1997; 90:869-73.

20. Okun N, Verma A, Demianczuk N. Gestational diabetes mellitus: Unresolved issues and further research directions. Can Fam Physician. 1997; 43:88-93.

21. Schwartz R. Hyperinsulinemia and macrosomia. $N$ Engl J Med. 1990; 323:340-2.

\begin{tabular}{|c|c|c|c|}
\hline \multicolumn{4}{|c|}{ AUTHORSHIP AND CONTRIBUTION DECLARATION } \\
\hline Sr. \# & Author-s Full Name & Contribution to the paper & Author $=$ s Signature \\
\hline 1 & $\begin{array}{l}\text { Aasma Naz Qureshi } \\
\text { Irfan Ahmed }\end{array}$ & $\begin{array}{l}\text { Conception and design, Statistical expertise, } \\
\text { Critical revision of the article for important } \\
\text { intellectual content. } \\
\text { Drafting of the article. }\end{array}$ & \\
\hline 3 & Ashok Kumar Lohano & $\begin{array}{l}\text { Data collection critical revision fo the article } \\
\text { for important intellectual content. }\end{array}$ & \\
\hline 4 & Farah Afroz & Drafting of the article & \\
\hline 5 & Khawer Hussain & Data collection & Clowr \\
\hline
\end{tabular}

